For further information about the conference program, registration, accommodations, and for abstract templates, contact: Dr. Chien-Min Wang, IUMRS-ICA94, Materials Research Laboratories, ITRI, Bldg. 77, 195 Chung-Hsing Rd., Sec. 4, Chutung, Hsinchu, Taiwan, ROC. Tel: 886-35-820216; Fax: 886-35-820217 or 820262.

The IUMRS-ICA meetings are sponsored by regional materials research societies located in Asia and organized yearly by each of the members in rotation under IUMRS auspices. Upcoming ICAs will be held in Korea (1995), India (1996), and Japan (1997).

News about IUMRS conferences and activities can be sent to: MRS Bulletin, Materials Research Society, 9800 McKnight Road, Pittsburgh, PA 152376006. Fax: (412) 367-4373.

\title{
Update: E-MRS Spring Meeting Offers Workshop on Advanced Materials Education
}

A special two-day workshop on Advanced Materials Education is being planned for the 1994 E-MRS Spring Meeting in Strasbourg, May 24-27. According to chairmen Gabriel M. Crean (National Microelectronics Research Centre, Ireland) and Jean-Pierre Massué (Council of Europe, France), the workshop's goal is to bring together leading materials science educators, researchers, and industrialists to discuss ways to develop "a materials science education roadmap for the 21st century."

Invited keynote talks will focus on the following topics:

Strategies in education for materials science and engineering;

Teaching materials for materials science and engineering courses;

European standardization of materials science curricula;
University-industry cooperation in curriculum design;

Undergraduate education in materials science and education; and International, European, and national policies in materials science and engineering education.

For further information about the workshop, contact the chairmen: Gabriel M. Crean, Director Postgraduate Education, National Microelectronics Research Centre, Prospect Row, Cork, Ireland. Tel: 353-21-276871; Fax: 353-21-270271. JeanPierre Massue, Council of Europe, Secretary General of the European Federation of Scientific Networks, 67006 Strasbourg Cédex, France. Tel: 88-88412614; Fax: 33-88-412787.

See the January 1994 MRS Bulletin, p. 36 , for information about the E-MRS Spring Meeting.

\section{FROM I̊̊ TO 60,000Å FILM MEASUREMENT SOLUTIONS BEGIN WITH RUDOLPH}

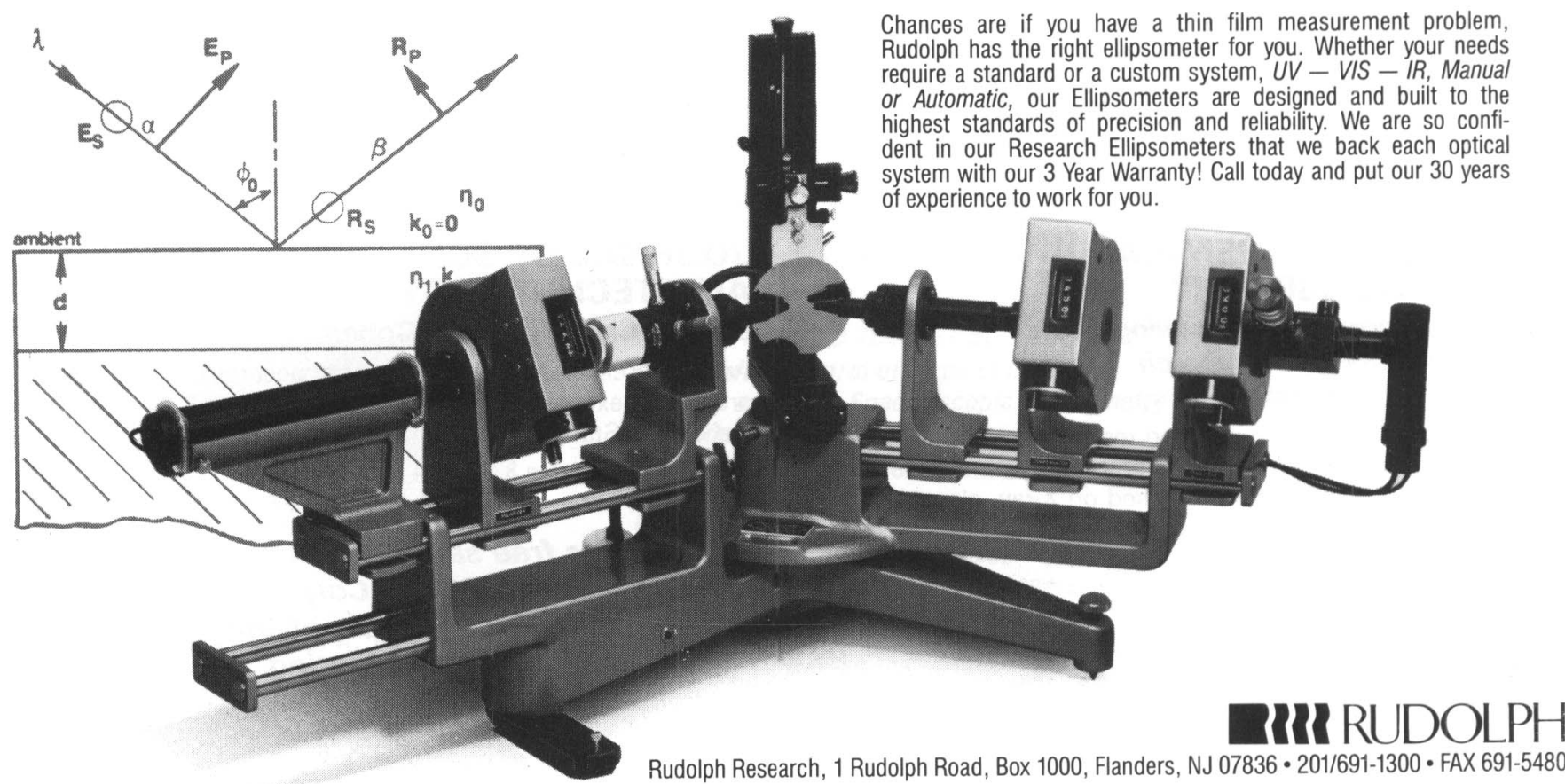

Circle No. 27 on Reader Service Card. 